\title{
Notes on the vocalizations of Western Whipbird (Psophodes nigrogularis)
}

Peter Boesman

In the following we briefly analyze and compare voice of the different races of Western Whipbird (Psophodes nigrogularis). We also try to quantify the extent of any vocal differences using the criteria proposed by Tobias et al. (2010), as a support for taxonomic review. We have made use of sound recordings available on-line from Xeno Canto (XC) and Macaulay Library (ML).

Song of all races (presumably a duet) is a repeated phrase of well-spaced short notes, some burry and some clear, typically going up and down in pitch. An overview of song per race, illustrated with sonograms:
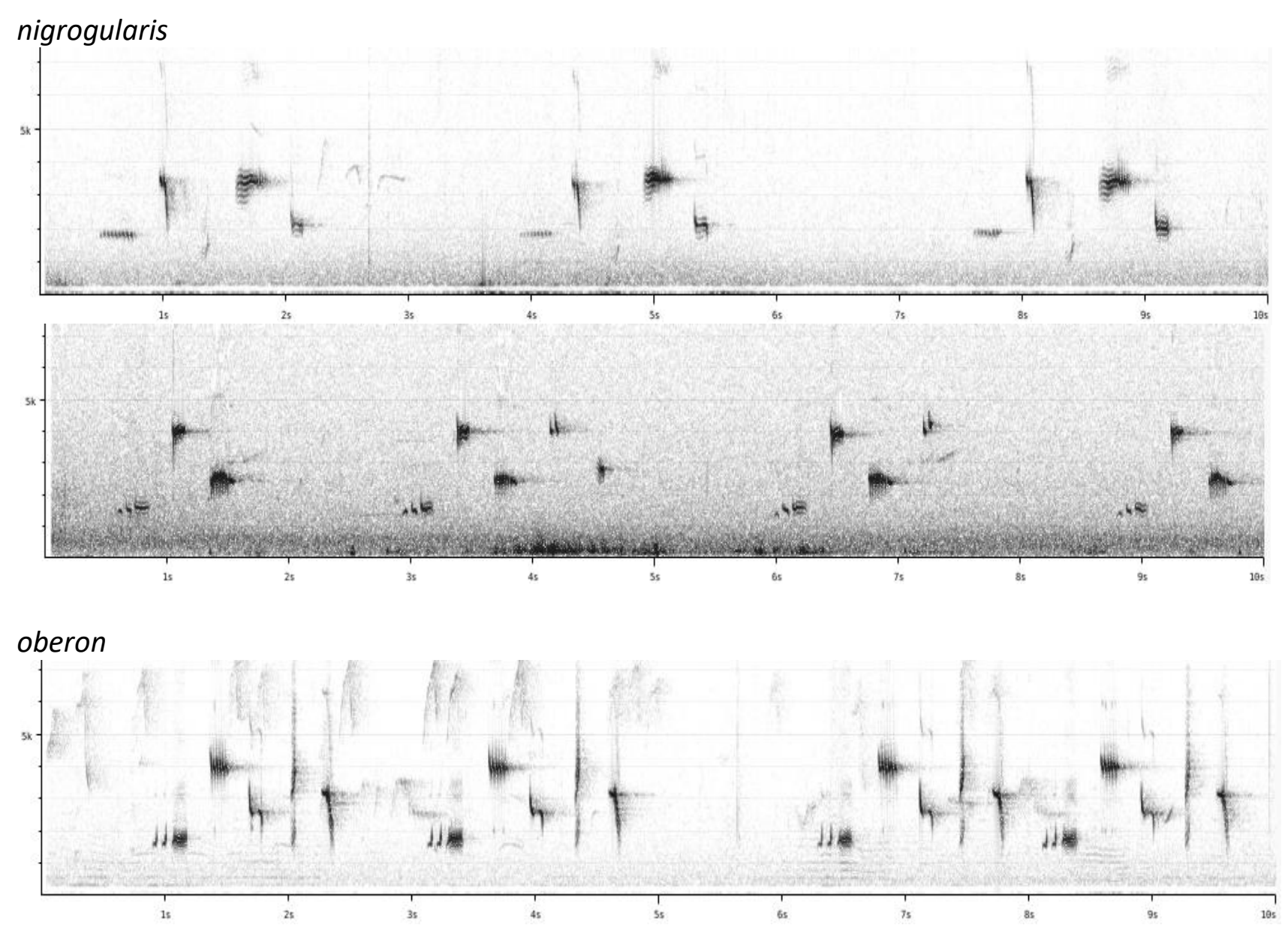
HANDBOOK OF THE

BIRDS PF/THE WORLD

ORNITHOLOGICAL NOTES

Alive

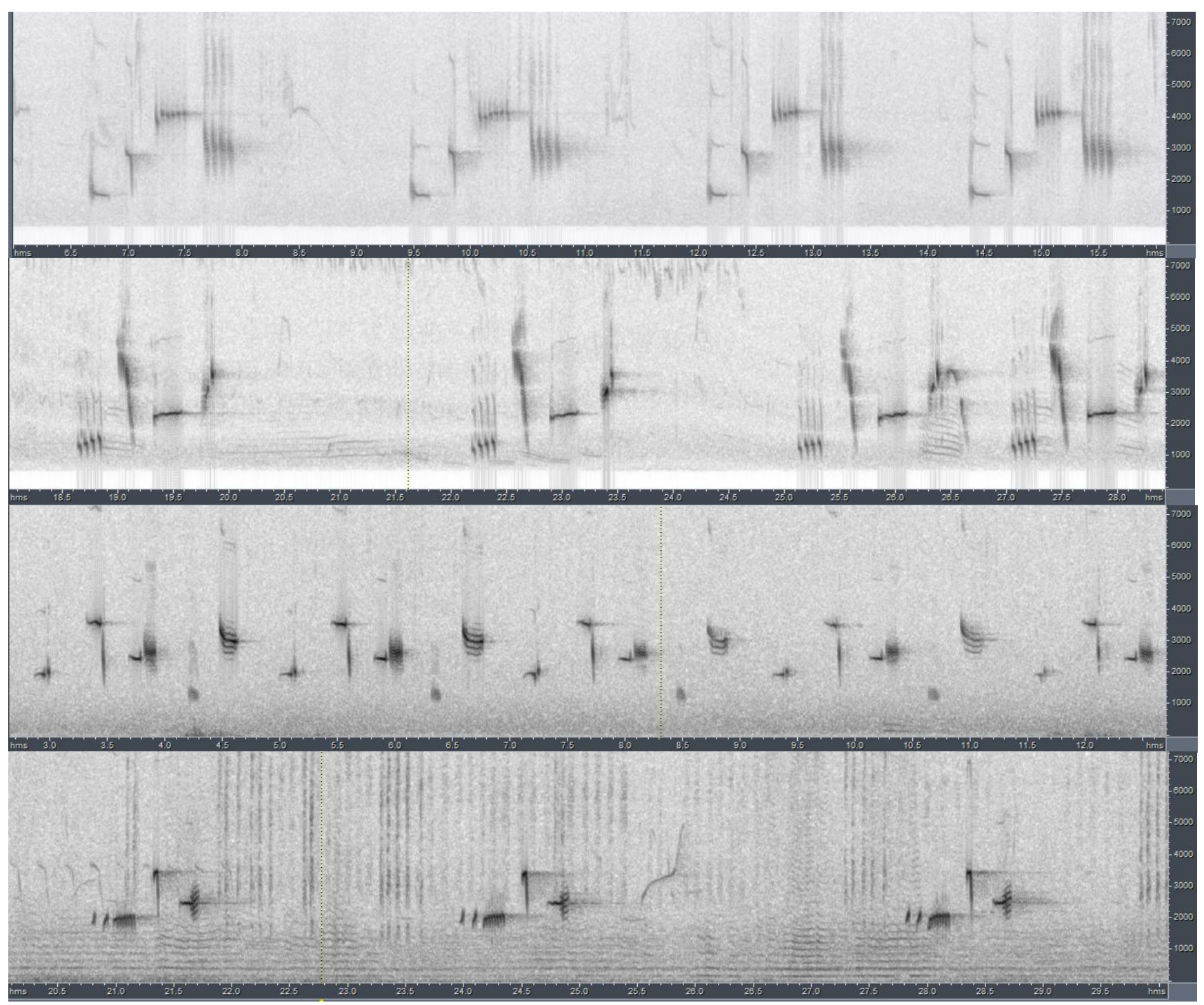

leucogaster

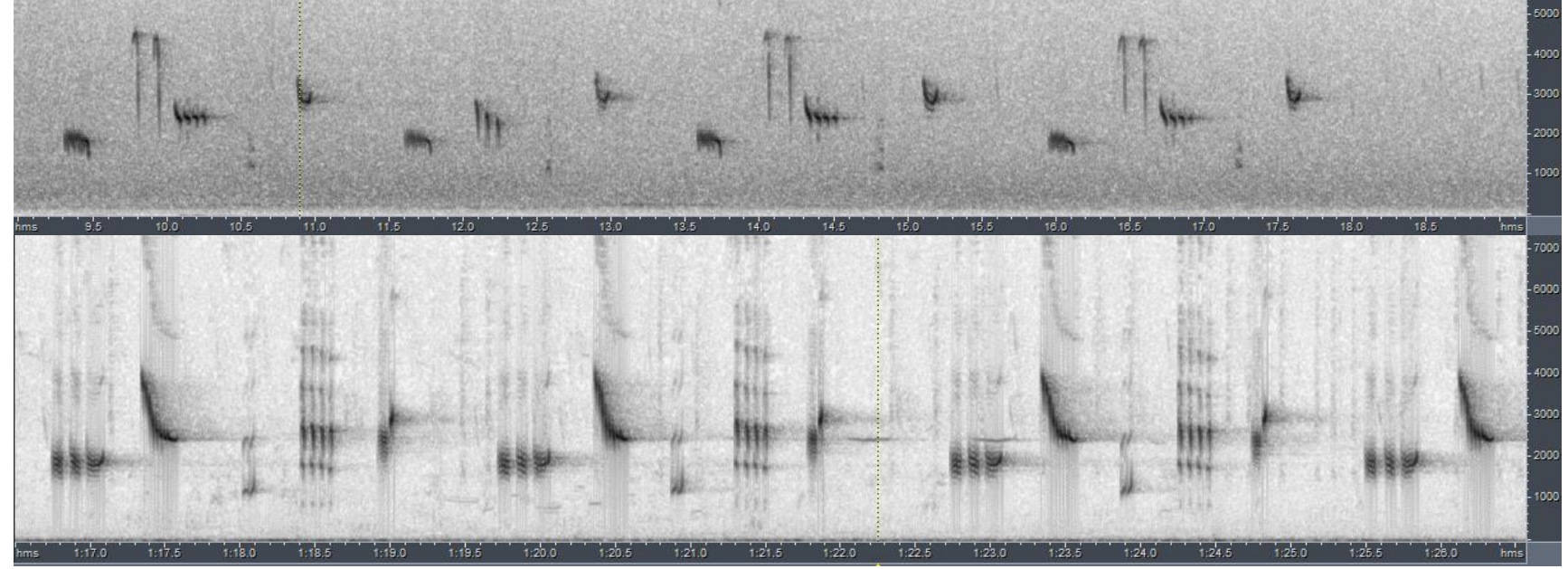




\section{HANDBOOK OF THE \\ Allue}

\section{ORNITHOLOGICAL NOTES}

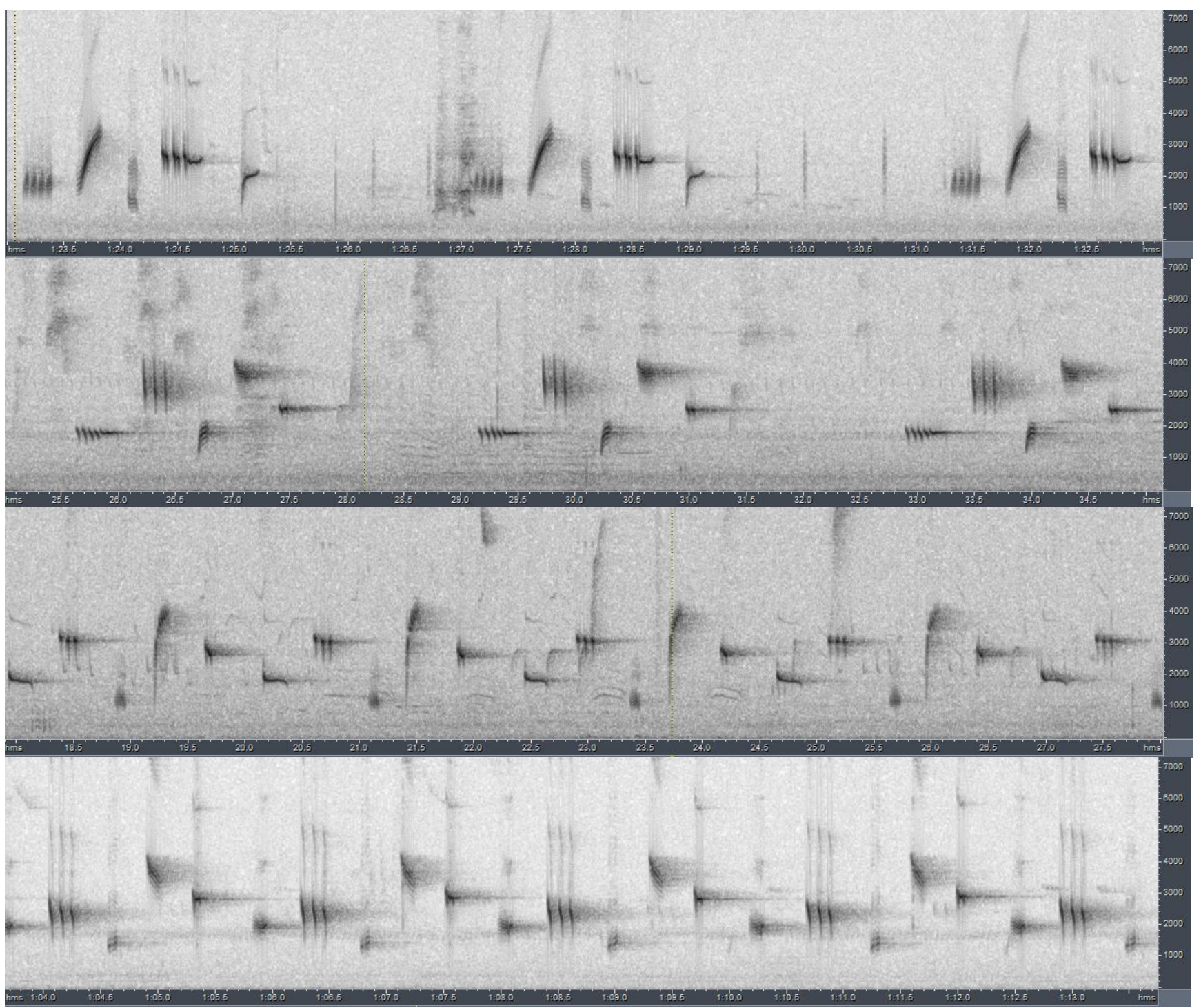

lashmari

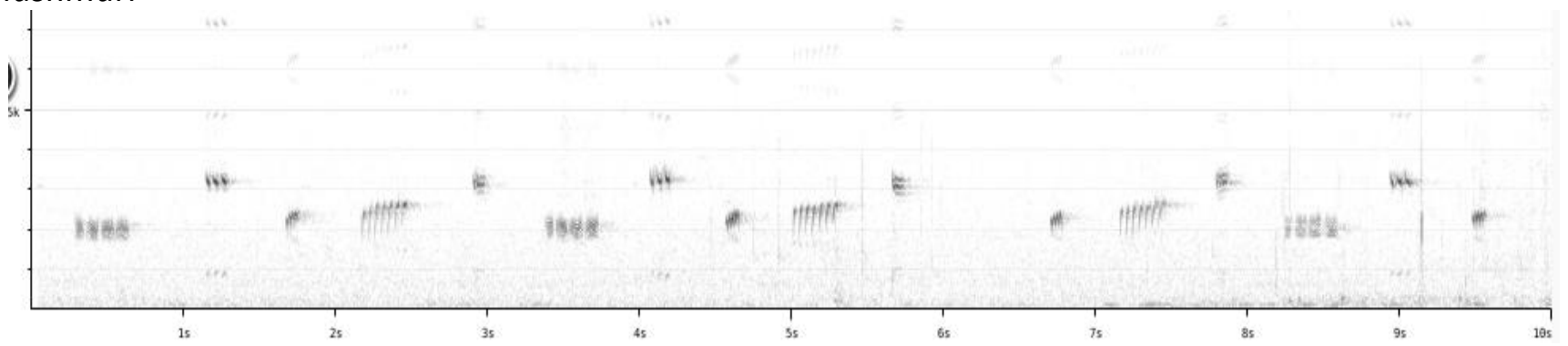

Birds of SW Australia (nigrogularis/oberon) typically sing a phrase of 4-5 notes repeated with variable intervals for a longer period. Only occasionally the pause between phrases is the same as space between notes, while this is rather common in leucogaster/lashmari. Also, song of leucogaster seems on average slightly slower.

We measured the longest pause between notes inside song strophes, leading to:

leucogaster: Av 0.39s SD $0.12(n=7)$

W Australia: Av 0.28s SD $0.07(n=5)$

resulting in an effect size of 1.12 -> score 1 
All in all, vocal differences among races seem to be minor.

This note was finalized on 8th July 2016, using sound recordings available on-line at that moment. We would like to thank in particular the sound recordists who placed their recordings for this species on XC and ML: Pieter de Groot Boersma, Mark Harper, Nick Talbot and the staff of Macaulay Library for forwarding the recordings of David Stewart.

\section{References}

Tobias, J.A., Seddon, N., Spottiswoode, C.N., Pilgrim, J.D., Fishpool, L.D.C. \& Collar, N.J. (2010). Quantitative criteria for species delimitation. Ibis 152(4): 724-746.

\section{Recommended citation}

Boesman, P. (2016). Notes on the vocalizations of Western Whipbird (Psophodes nigrogularis). HBW Alive Ornithological Note 415. In: Handbook of the Birds of the World Alive. Lynx Edicions, Barcelona. (retrieved from http://www.hbw.com/node/1253817 on 6 December 2016). 